\title{
Non-Linear Multivariate Dependence between the Mexican Stock Market Index and the Exchange Rate: Efficiency Hypothesis and Political Cycle in Mexico (1994-2012) Semei Lepoldo Coronado Ramírez* \\ Universidad de Guadalajara, Centro Universitario de Ciencias Económico Administrativas, Departamento de Métodos Cuantitativos Rafael Romero-Meza \\ Universidad Autónoma de Chile, Facultad de Administración y Negocios Francisco Venegas-Martínez \\ Instituto Politécnico Nacional, Escuela Superior de Economía
}

(Received December 15, 2015, accepted April 06, 2016)

\begin{abstract}
This paper uses a multivariate extension of the non-parametric nonlinearity test from Hinich (1991) with the objective of investigating whether there is a nonlinear relation between the index of The Mexican Stock Exchange (IPC) and the peso/dollar exchange rate measured through the Cross-correlation and cross-correlation in the period 1994-2012 for three sub-periods of presidential administration. This method divides the sample into windows and provides information on nonlinear dependency. The main finding is that no significant cross-correlation windows are detected. However, time windows are observed with a significant cross bicorrelation, which suggests a non-linear and bidirectional relationship between the series. This paper concludes that for the three sub-periods of presidential administration both series maintain the same nonlinear and bidirectional relation for any change in the government with significant windows concentrated at the beginning of the presidential period regardless of the ruling party. Finally, It is important to note that the non-linear bidirectional periods were concentrated in the middle of the last Mexican presidential period, indicating that global external and economic financial factors affected this relationship.

JEL Classification : F31, C02, C12.

Key Words: Multivariate Non-Linear Models, Mexican Stock Market, Cross-Bicorrelation Hinich Test, Foreign Exchange Rate.

Dependencia multivariante no lineal entre el Índice de Precios y Cotizaciones de la Bolsa Mexicana de Valores y el tipo de cambio: Hipótesis de eficiencia y ciclo político en México (1994-2012)
\end{abstract}

Este trabajo utiliza una extensión multivariante de la prueba no paramétrica de no linealidad de Hinich (1991 con el objetivo de investigar si existe una relación no lineal entre el índice de la Bolsa Mexicana de Valores (IPC) y el tipo de cambio peso/dólar medida a través de la correlación cruzada y la bicorrelación cruzada en el periodo 1994-2012 durante tres subperíodos de administración presidencial. Este método divide la muestra en ventanas y proporciona información sobre la dependencia no lineal. El principal hallazgo es que no se

* Centro Universitario de Ciencias Económicas Administrativas. Periférico Norte. No 779. Núcleo Universitario los Belenes, Zapopan, Jalisco. Tel. (0133) 377033 00. Ext. 25287. Correo Electrónico:semei.coronado@academicos.udg.mx 
detectan ventanas de correlación cruzada significativas. No obstante se observan ventanas de tiempo con una bicorrelación cruzada significativa, lo que sugiere una relación no lineal y bidireccional entre las series. Este trabajo concluye que para los tres subperíodos de administración presidencial ambas series mantienen la misma relación no lineal y bidireccional para cualquier cambio en el gobierno con ventanas significativas concentradas al principio del período presidencial sin importar el partido gobernante. Por último es importante destacar que los períodos no lineales bidireccionales se concentraron a mediados del último período presidencial mexicano, lo que indica que los factores financieros externos y económicos globales afectaron esta relación.

Clasificación JEL: F31, C02, C12.

Palabras clave: Modelos Multivariantes no Lineales, Bolsa Mexicana de Valores, Prueba de Bicorrelación Cruzda de Hinich, Tipo de cambio.

\section{Introduction}

Much research has been done to examine the relationship between the spot exchange rate and stock price in various economies. Most of the findings state that when the value of the local currency depreciates compared with major currencies, such as the dollar, euro or pound sterling, the local stock market will increase. The decreasing of the local currency value boosts firm competitiveness through a greater export, which increases their cash flow, projects and debt level; such increases enhances the value of the firm (Josep, 2002) and, thus, raises the stock prices. On the other hand, the portfolio explanation argues that an increase in stock prices induces investor demand for more domestic assets, which appreciates the local currency. This relationship implies that share prices and the exchange rate are negatively related (Yau and Nieh, 2006).

Empirical studies on political cycles, which have primarily been conducted for the United States, find that elections also affect stock market performance. Previous studies have shown that returns on stock tend to increase during the last two years of a presidency compared with the first years (Umstead, 1977; Allivine and ONeill, 1980; Huang, 1985). Recent studies have shown that the performance of stock returns of American companies is typically better under a Democrat than Republican government (Gärtner and Wellershoff, 1999; SantaClara and Valkanov, 2003). Evidence for Latin America is scarce. Work by Bonilla et al. (2013) considers the importance of the presidential candidate's characteristics for Chile in 2010. In this regard, the Mexican case is interesting due to the change in the ruling party during the period analyzed.

This research examines the political cycle in Mexico and the non-linear relation between the stock returns and the exchange rate. In particular, we show that the relationship between these financial variables is influenced by the governing coalition.

On the other hand, international studies, (Aggarwal, 1981; Yang and Doong, 2004; Mishra, et al., 2007) show a relationship that originates in the exchange rate and is transmitted to the stock market or vice-versa; however, the direction of such variables is unclear (Yau and Nieh, 2006). This relationship has been studied with two time-series methodologies, autoregressive vectors and/or Granger causality, to detect a unidirectional or bidirectional relationship in either developed or emerging economies in Asia and Latin America, see, for instance: Abdalla and Murinde (1997); Ajayi et al. 
(1996); Granger et al. (2000); Doong et al. (2005), Pan et al. (2007); Guzmán et al. (2007); Agrawal et al. (2010); and Diamandis and Drakos (2011).

Typically the common used methods are primarily linear models; however, several studies propose a non-linear dependence. The first non-linearity studies on economics and finance include Brock (1986) and Hsieh (1989a,b) and Scheinkman and LeBaron (1989a,b). The number of studies has grown in recent years; see, for instance: Brock et al. (1987); Brock et al. (1996); Hinich (1982); Hinich and Patterson (1985); Hsieh, (1991); Abhyankar et al. (1995); Opong et al. (1999); Kosfeld and Robé (2001); Cajueiro and Tabak (2004); Lim (2007); Ammerman and Patterson (2003); Antoniou et al. (1997); Panagiotidis (2005); Lim and Hinich (2005); Bonilla et al. (2006); RomeroMeza et al. (2007); Hinich and Serletis (2007); Lim and Brooks (2011); Serletis et al. (2012).

Previous studies have shown episodic non-linear univariate dependence in various financial markets and for various economic and financial time series; however, multivariate non-linear dependence has been less studied, even fewer investigations have been conducted on emerging markets. To the best of our knowledge, multivariate non-linear dependence has not been studied for the exchange rate and stock market returns in an emerging economy, such as in Mexico, nor has the impact from the political cycle on such financial variables been investigated.

The classical model for a time series assumes that errors are independent and identically distributed (i.i.d.) with first- and second-order moments. Non-compliance with this condition can yield causality because such assumptions are difficult to realize for higher-order non-zero probability distributions or asymmetries during certain time periods.

The number of applications for non-linear methodologies has recently increased due to the role of these approaches in detecting false linear causality. The various advantages for such applications over linear methodologies include non-parametric calculations. Thus, specific probability distributions are not used to explain causality or to eliminate negative and positive effects from independent variables on the dependent variable (Diks and Panchenko, 2006; Bekiros and Diks, 2008; De Gooijer and Sivarajasingham, 2008; Anoruo, 2011; Marinazzo et al., 2008; Bai et al., 2010; Laloux et al., 1999; Plerou et al., 1999; Sharifi et al., 2004; Wilcox and Gebbie, 2007; Nakayama and Iyetomi, 2008; Conlon et al., 2009; Tóth and Kertész, 2005; Altay, 2003).

A relatively recent and less-explored methodology is the cross-bicorrelation test between variable pairs (financial and non-financial type) to detect a non-linear dependence between two series and discern lead/lag relationships between such variables (Brooks and Hinich, 1999; Czamanski et al., 2007; Serletis et al., 2012). This test is a multivariate extension of Hinich's (1996) bicorrelation statistic, which is aimed at detecting non-linear characteristics in pairs of series. The method proposed herein can detect any form of third-order non-linear dependence between two series; thus, it is an additional methodological tool for investigating Granger-type causality from a non-linear perspective. This paper analyzes time series using this recent methodology, cross-correlation and cross-bicorrelation, which 
facilitates identification of the potential causal relationships for different periods throughout the series.

For the exchange rate and stock returns in Mexico for the full period available $(01 / 03 / 1994-10 / 29 / 2012)$, we study the non-linear dependence between variables (cross-bicorrelation method developed from Brooks and Hinich, 1999). Therefore, identifying such non-linear dependence would allow us to question the market efficiency hypothesis; it also supports the need to generate new predictive models because the traditional linear models do not consider such dependence. Moreover, we applied this model to three time sub-periods of the full sample that do not overlap to find patterns with the political cycle (three government administrations) in Mexico.

The Mexican case is interesting because it is a medium-size emerging economy that also depends on the United States due to its geographic location and trading volume. Additionally, over the past 18 years, the ruling party in Mexico has been changed. In the past, the currency often depreciated with each change in government. However, each entering party has encountered different challenges, producing a stable exchange rate and strengthened the stock market. Thus, this methodology may contribute to the literature on political cycles.

This paper is organized into five sections: section 2 presents the methodology; section 3 provides the data; section 4 discusses the results; finally, section 5 presents the conclusions and acknowledge limitations.

\section{Proposed Methodology}

We will be concerned with a sample of two stationary series $X\left(t_{k}\right)$ and $Y\left(t_{k}\right)$ of size $N$. Each series is divided into small non-overlapping frames (windows) with equal lengths. Here, $t$ is an integer, and $k$ is the $k-t h$ window. Both series had joint stationary covariances that are standardized. The hypotheses are as follows: $H_{0}$ : the series $X\left(t_{k}\right)$ and $Y\left(t_{k}\right)$ are independent pure white noise, and $H_{1}$ : the series $X\left(t_{k}\right)$ and $Y\left(t_{k}\right)$ have the non-zero cross-covariance $C_{X Y}(r, s)=$ $E\left[X\left(t_{k}\right) Y\left(t_{k+r}\right)\right]$ or cross-bicovariance $C_{X X Y}(r, s)=E\left[X\left(t_{k}\right) X\left(t_{k+r}\right) Y\left(t_{k+s}\right)\right]$.

Notice that due to the invariance in $C_{X X Y} \quad(r, s)=E\left[X\left(t_{k}\right) X\left(t_{k+r}\right)\right.$ $\left.Y\left(t_{k+s}\right)\right]$ for the fixed permutations in the first two factors, the expected value is the two-lag function, that is, $C_{X X Y}(r, s)=C_{X X Y}(-r, s)$. If the maximum lag used is $L<N$, then the primary domain for the bicovariance is the rectangle $1<r<L,-L<s<L$ (Brooks and Hinich, 1999).

Observe now that under the null hypothesis, $X\left(t_{k}\right)$ and $Y\left(t_{k}\right)$ are pure white noise. Therefore, $C_{X Y}(r)=C_{X X Y}(r, s)=0$ for all $r, s>0$. We know that a series pair is dependent when the series includes a second or third lag such that $C_{X Y}(r) \neq 0$ or $C_{X X Y}(r, s) \neq 0$ for $r$ or a pair of values $(r, s)$, respectively. Therefore, cross-correlation and cross-bicorrelation are as follows:

$$
C_{X Y}(r)=\frac{1}{(N-r)} \sum_{k=1}^{N-r} X\left(t_{k}\right) Y\left(t_{k+r}\right), r \neq 0
$$

and

$$
C_{X X Y}(r)=\frac{1}{N-m} \sum_{k=1}^{N-m} X\left(t_{k}\right) X\left(t_{k+r}\right) Y\left(t_{k+s}\right)
$$


where $m=\max (r, s)$.

The cross-bicorrelation can be thought as a correlation between the current value for one series and the prior cross-correlation value between the two series. The sum for the second order case, given in (2), does not include the contemporary term and is generated using the residue from the adjusted autoregressive process to filter the univariate auto-correlated structure such that the contemporary correlations do not produce a rejection. For the third-order analyses, given in (2), we used an estimate of the residuals of a bivariate vector autoregressive model, which includes a contemporary term in one equation. We use the pre-whiting step to eliminate evidence of linear correlation or cross-correlation so that the remaining dependence between the series should be non-linear. Thus, we can show that:

$$
\begin{gathered}
E\left[C_{X Y}(r)\right]=0, \\
E\left[C_{X X Y}(r, s)\right]=0 \\
E\left[C_{X Y}^{2}(r)\right]=\frac{1}{M-r} \\
E\left[C_{X X Y}^{2}(r)\right]=\frac{1}{M-m}
\end{gathered}
$$

Under the null hypothesis, let $L=N^{c}, 0<c<0.5$. The statistics for the non-zero cross-correlation and cross-bicorrelation are as follows:

$$
H_{X Y}(N)=\sum_{r=1}^{L}(N-r) C_{X Y}^{2}(r)
$$

and

$$
H_{X X Y}(N)=\sum_{S=-L}^{L} \sum_{r=1}^{L}(N-m) C_{X X Y}^{2}(r, s), s \neq-1,1,0 .
$$

respectively. These statistics composed sets or compound tests for crosscorrelation and cross-bicorrelation (similar to the Ljung-Box $Q^{*}$, which was applied for autocorrelation), where the number of correlations examined is $L$, and the number of cross-bicorrelations examined is $L(2 L-1)$. According to Hinich (1996), $H_{X Y}$ and $H_{X X Y}$ are asymptotically $\chi^{2}$ with $L$ and $L(2 L-1)$ degrees of freedom, respectively, as $N \rightarrow \infty$.

\section{Data Features}

The sample includes the IPC from the Mexican Stock Exchange (BMV, its initials in Spanish) and the Mexican peso/US dollar exchange rate (TC, its initials in Spanish) during 01/03/1994-10/29/2012 with 4,735 observations. We calculate the logarithmic difference in stock prices, $R C=\ln \left(\frac{p_{t}}{p_{(t-1)}}\right)$, and they are subsequently standardized. To avoid linear dependence for the innovations, we adjusted the residuals from each series to an autoregressive 
process $A R(p)$; we preferred to choose the better $p$ in accordance with the Schwarz criterion $(S C)$. In contrast to other statistics, the Schwarz criterion is consistent for a particular $A R(p)$ and null hypothesis that generates a linear mechanism (Panagiotidis and Pelloni, 2003). This criterion optimizes lag selection to avoid over-adjustment. This is more robust than the Akaike information criterion $(A I C)$, and, therefore, the model with the lowest $S C$ is selected. Thus, we adjuste each series pair to different types of $A R(p)$ and different bivariate autoregressive vectors, $B V A R(r, s)$, to determine the cross-bicorrelation.

The data was obtained from the Bloomberg database and Banco de México (Mexican Central Bank), respectively. Figure 1 shows the IPC and TC series in logarithmic terms. For certain periods, they show the same behavior, but for others, they show an inverse performance. The aggregate indicates a positive correlation between such variables. Figure 2 shows the performance in logarithmic terms for each series.

Figure 1. Daily Series for the IPC and TC during 01/03/1994-10/29/2012.

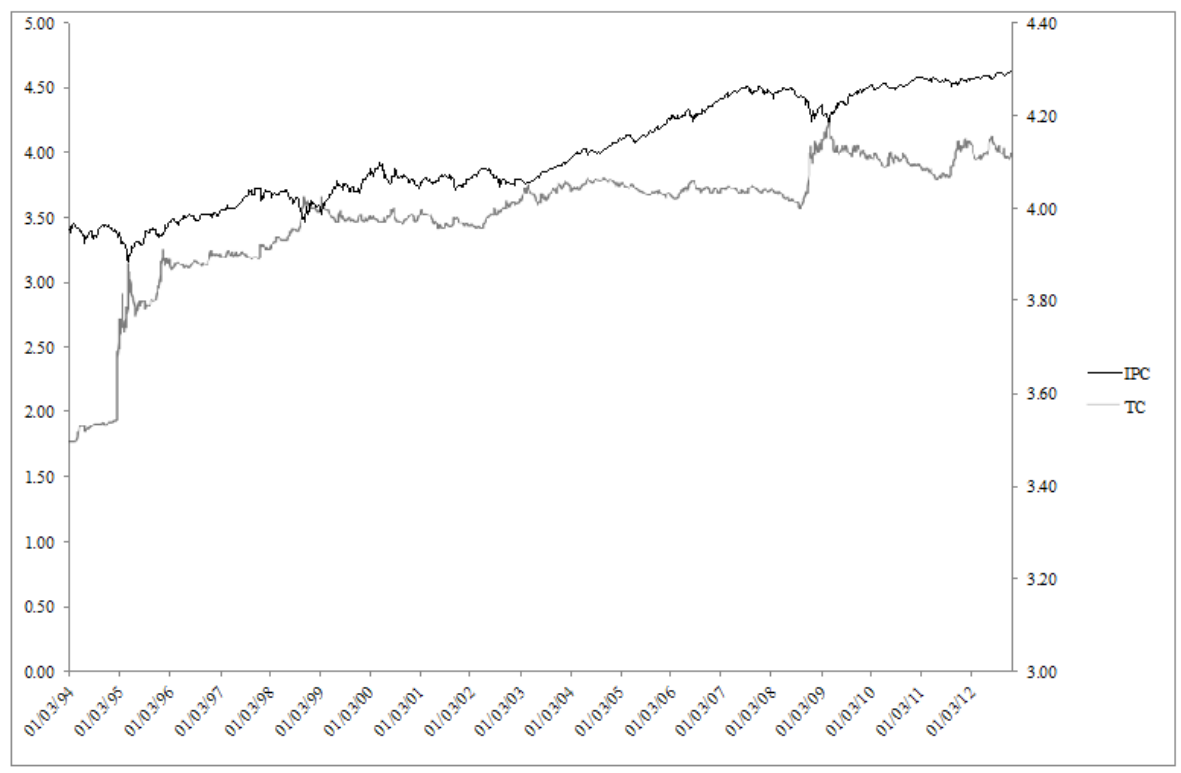

Fuente: Elaboración propia en Fortran. 
Figure 2. Daily Performance Logarithmic Scale for the IPC and TC during. 01/03/1994-10/29/2012.

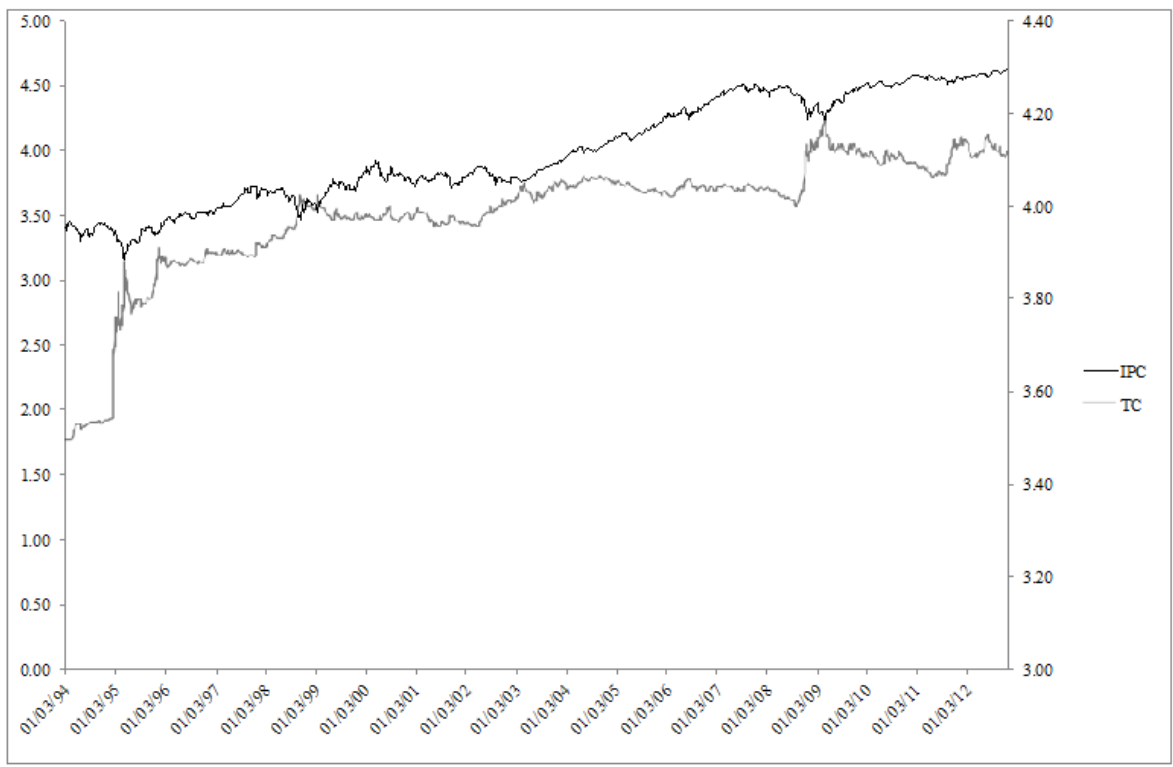

Fuente: Elaboración propia en Fortran.

\section{Empirical Results}

To reject the null hypothesis in (1) in accordance with the test from (2), we analyzed the data series pair. First, we study the series for the entire period; subsequently, the entire series was divided into three periods that correspond to the presidential periods in Mexico, except for the last period, which is incomplete.

The two series are then divided into windows with 25 observations, which generated 189 windows for the entire analysis. The first and second periods have 60 windows, and the last period has 59 non-overlapping windows with $\mathrm{c}=$ 0.25 , a 0.01 threshold, a first-order autoregressive vector $(B V A R)(1,1)$ for the first three periods and a $B V A R(0,0)$ for the last period (see Table 1 ).

An important result from this study is that we did not detect significant cross-correlation periods for the entire series; we also did not detect such periods for the three presidential periods. However, we did observe periods with cross-bicorrelation, which are indicated in Table 1 column seven. In the same table, column 10 shows the correlation between the cross-bicorrelation pairs, which demonstrates high correlation between the series pair, which primarily indicates a non-linear and bidirectional relationship. 
Table 1. Results from the Bi-correlation for the Entire Series and the 3 Periods.

\begin{tabular}{|c|c|c|c|c|c|c|c|c|c|}
\hline \multirow[t]{2}{*}{ Serie } & \multirow[t]{2}{*}{ Threshold } & \multirow{2}{*}{$\begin{array}{c}\text { AR } \\
\text { Adjusted }\end{array}$} & \multirow[t]{2}{*}{ Windows } & \multirow{2}{*}{$\begin{array}{c}\text { Windows } \\
\text { size }\end{array}$} & \multirow{2}{*}{$\begin{array}{c}\text { Significant } \\
\text { correlation } \\
\text { based on the } p \\
\text { value }\end{array}$} & \multirow{2}{*}{$\begin{array}{l}\text { Total numbers of } \\
\text { windows with } \\
\text { significant }\end{array}$} & \multicolumn{2}{|c|}{ Windows with bicorrelation } & \multirow{2}{*}{$\begin{array}{c}\begin{array}{c}\text { Correlatior } \\
\text { pairs }\end{array} \\
\text { (xxy,yy) }\end{array}$} \\
\hline & & & & & & & $\mathrm{xxy}$ & yyx & \\
\hline $\mathrm{IPC} / \mathrm{TC}$ & $0[1]$ & 2 & 189 & 25 & $\begin{array}{c}\text { No significant } \\
\text { cross- }\end{array}$ & $30(15.9 \%)$ & $17(9.4 \%)$ & $13(6.9 \%)$ & 0.64 \\
\hline $\mathrm{IPC}_{1} / \mathrm{TC}_{1}$ & & & 60 & & correlations & $10(16.6 \%)$ & $5(8.3 \%)$ & $5(8.3 \%)$ & 0.62 \\
\hline $\mathrm{IPC}_{2} / \mathrm{TC}_{2}$ & & & 60 & & & $11(18.3 \%)$ & $5(8.3 \%)$ & $6(10.4 \%)$ & 0.55 \\
\hline $\mathrm{IPC}_{3} / \mathrm{TC}_{3}$ & & & 59 & & & $20(33.9 \%)$ & $11(18.6 \%)$ & $9(15.3 \%)$ & 0.59 \\
\hline
\end{tabular}

Fuente: Elaboración propia en Fortran.

In Table 2, we show the significant windows wherein. We identified multivariate non-linear dependence detected through cross-bicorrelation for the four periods analyzed. We observed a non-linear relationship in the six windows at the beginning of the entire series, but there is one window after two year which was again detected after two year and approximately ten years later and coincided with a decreased IPC and increased TC, as shown in Figure 1.

In the first presidential period, the majority of the significant windows were detected at the beginning of the period, which is similar to the entire series. Period 3 corresponds to the second presidential period and yielded the same performance as the previously analyzed periods, wherein the bidirectional behavior was concentrated at the beginning of the period; a significant window was also detected at the end of the six-year period. Finally, the last six years analyzed did not behave the same as the other periods, wherein the non-linear relationship was concentrated in the middle of the period, which is consistent with the behavior illustrated in Figure 1, showing a decreasing IPC and increasing exchange rate.

Table 2. Significant Windows from the Cross-Bicorrelation.

\begin{tabular}{|c|c|c|c|c|}
\hline & $\mathrm{IPC} / \mathrm{TC}$ & $\mathrm{IPC}_{1} / \mathrm{TC}_{1}$ & $\mathrm{IPC}_{2} / \mathrm{TC}_{2}$ & $\mathrm{IPC}_{3} / \mathrm{TC}_{3}$ \\
\hline $\begin{array}{c}\text { Significant } \\
\text { windows for the } \\
\text { pair (xxy.yyx) }\end{array}$ & $\begin{array}{l}01 / 04 / 94-02 / 07 / 94 \\
11 / 24 / 94-01 / 02 / 95 \\
01 / 04 / 95-02 / 06 / 95 \\
02 / 07 / 95-03 / 14 / 95 \\
03 / 15 / 95-04 / 21 / 95 \\
10 / 18 / 95-11 / 24 / 95 \\
10 / 20 / 97-11 / 24 / 97 \\
01 / 04 / 99-02 / 09 / 99 \\
09 / 24 / 08-10 / 29 / 08 \\
03 / 26 / 09-05 / 05 / 09\end{array}$ & $\begin{array}{l}12 / 02 / 94-01 / 06 / 95 \\
01 / 09 / 95-02 / 10 / 95 \\
02 / 13 / 95-03 / 20 / 95 \\
08 / 13 / 98-09 / 02 / 98\end{array}$ & $\begin{array}{l}08 / 30 / 01-10 / 09 / 01 \\
06 / 24 / 02-07 / 29 / 02 \\
07 / 30 / 02-09 / 03 / 02 \\
07 / 07 / 06-08 / 11 / 06\end{array}$ & $\begin{array}{l}08 / 14 / 08-09 / 19 / 08 \\
09 / 22 / 08-10 / 24 / 08 \\
10 / 27 / 08-12 / 01 / 08 \\
01 / 08 / 09-02 / 13 / 09 \\
02 / 16 / 09-03 / 23 / 09 \\
03 / 24 / 09-04 / 29 / 09 \\
09 / 19 / 11-10 / 18 / 11\end{array}$ \\
\hline
\end{tabular}

Fuente: Elaboración propia en Fortran. 
The disparate behavior in the final period apparently disrupts the political cycle detected and may be due to substantial external factors, such as the subprime crisis.

\section{Conclusions}

Herein, we investigated the non-linear relationship between the exchange rate and stock market return for Mexico for the entire sample during 1994-2012 and the three sub-periods, wherein the ruling party changed. We expect that this methodology can be used for empirical studies on political cycles and market efficiency because it considers elements that were previously not considered, such as multivariate non-linear dependence and a window-base investigation. Based on such considerations, we can discern statistically significant similarities and differences for such series. This methodology is recent (Brooks and Hinich, 1999) and has not been used for economic series in emerging markets; furthermore, it facilitates analyses for specific time windows, which provides information that is otherwise unavailable from other methods.

The results indicate a non-linear relationship detected through a significant cross-bicorrelation for distinct periods; though, there are no significant periods with cross-correlations. This cross-bicorrelation is high and exceeds $55 \%$, which allowed us to search for periods with correlation between $(X X Y, Y Y X)$, and we detected periods with a non-linear relationship regardless of the ruling party.

For the first presidential period studied, which corresponded to the government controlled by the Institutional Revolutionary Party (PRI, its initials in Spanish), the bidirectional non-linear periods were at the beginning and end of the six-year period, which was consistent with the behavior during the subsequent presidential period; although, the ruling party was changed to the National Action Party (PAN, its initials in Spanish). However, during the last presidential period investigated, we detected significant windows towards the middle of the term; we speculate that this disparate behavior was due to the United States mortgage crisis.

Our results are consistent with previous studies on non-linearity, which are primarily univariate, such as Bonilla et al. (2006, 2011), Romero-Meza et al. (2007), Panagiotidis and Pelloni (2003) and Coronado and Gatic, (2011). For Latin American countries, few investigations have empirically studied political cycles, except for Bonilla et al. (2013). The method used herein facilitates such studies through the aforementioned new dimensions.

It would be interesting to study the political and economic causes for the cross-non-linear events more in-depth. This paper can be extended to consider a United States stock market index, such as the S\&P500, given the geographic proximity and high interdependence between Mexico and the United States.

The results herein have implications for the empirical models that are typically used for such studies because traditional models may not adequately represent the data in which cross-non-linear dependence episodes are detected. For non-linear dependence, we can consider procedures that may use the dependence detected and to design investment strategies that exceed passive strategies, such as buy and hold. Furthermore, it would be 
interesting to study additional emerging markets with government changes to discern multivariate non-linear dependences and, if such dependencies are detected, whether they occur at similar times in different markets. Ideally, one could initially investigate the Latin American markets because the majority of such countries are relatively young democracies subject to political and economic whims.

Additional research in this area may include specific economic sectors, such as the tradable and non-tradable sectors, or specific industries; we expect that the relationship between the exchange rate and stock market returns differs depending on the type of economic activity. Likewise, specific companies could also be studied. These extensions could improve predictive models and portfolio assignments for institutional investors.

\section{Bibliografía}

Abdalla, I. \& Murinde, V. (1997). Exchange Rate and Stock Price Interactions in Emerging Financial Markets: evidence on India, Korea, Pakistan and the Philippines. Applied Financial Economics, 7, 25-35.

Abhyankar, A., Copeland, L. \& Wong, W. (1995). Nonlinear Dynamics in Real-Time Equity Market Indices: Evidence from the United Kingdom, Economic Journal 105, 864-880.

Aggarwal, R. (1981). Exchange Rates and Stock Prices: A Study of the US. Capital Markets under Floating Exchange Rates. Akron Business and Economic Review, 12, 7-12.

Agrawal, G., Srivastav, K. \& Srivasta, A. (2010). A Study of Exchange Rates Movement and Stock Market Volatility. International Journal of Business and Management, 5(12), 62-73.

Ajayi, R. A. \& Mougoue, M. (1996). On the Dynamic Relation between Stock Prices and Exchange Rates. Journal of Financial Research, 19, 193-207.

Allvine, F. \& O'Neill, D. (1980). Stock Market Returns and the Presidential Cycle. Financial Analysts Journal, 36, pp. 49-61

Altay, E. (2003). Cross-Autocorrelation between Small and Large Cap Portfolios in the Gand Turkish Stock Markets. Journal of Financial Management and Analysis, 17(2), 2004.

Ammermann, P. \&. Patterson, D. M. (2003), The Cross-Sectional and Cross-Temporal Universality of Nonlinear Serial Dependencies: Evidence from World Stock Indices and the Taiwan Stock Exchange. Pacific-Basin Finance Journal 11, 175-195.

Anoruo, E. (2011). Testing for Linear and Nonlinear Causality between Crude Oil Price Changes and Stock Market Returns. International Journal of Economic Sciences and Applied Research, 4(3), 75-92

Antoniou, A., Ergul, N. \& Holmes, P. (1997) Market Efficiency, Thin Trading and Non-Linear Behaviour: Evidence from an Emerging Market. European Financial Management, 3(2), 175-190.

Bai, Z., Wong, W. \& Zhang, B. (2010). Multivariate Linear and Nonlinear Causality Tests. Mathematics and Computers in Simulation, 81(1), 5-17.

Bekiros, D. \& Diks, C. (2008). The Nonlinear Dynamic Relationship of Exchange Rates: Paramteric and Nonparametric Causality Testing. Journal of Macroeconomics, 30(4) 1641-1650.

Bonilla, C. A., Contreras, H. \& Sepulveda, J. (2013). Financial Markets and Politics: The Piñera Effect on the Chilean Capital Market. Forthcoming in Emerging Markets Finance and Trade.

Bonilla, C. A., Romero, R. \& Gutierrez, E. (2011), Episodic Non-Linearities and Market Efficency in the Mexican Stock Market, The Manchester School, 79, 367-380.

Bonilla, C.A., Romero-Meza, R. \& Hinich, M. (2006). Episodic Nonlinearity in Latin American Stock Market Indices. Applied Economics Letters 13, 195 - 199. . 
Brock, W.A., Dechert, W.D., \& LeBaron, B. (1987). A Test for Independence based on the Correlation Dimension, Mimeo. Department of Economics, University of Wisconsin at Madison, and University of Houston.

Brock, W.A., Dechert, W.D., \& LeBaron, B. (1996). A Test for Independence based on the Correlation Dimension. Econometric Review, 15, 197-235.

Brooks, C. \& Hinich, M. (1999). Cross-Correlation and Cross-Bicorrelations in Sterling Exchange Rates. Journal of Empirical Finance, 6(4), 385-404.

Cajueiro, D. O. \& Tabak, B. M. (2004). Ranking efficiency for Emerging Markets. Chaos, Solutions and Fractals, 22, 349-352.

Chakraborti, A., Muni, I. Patriarca, M. \& Abergel, F. (2011). Econophysic Review: I. Empirical Facts. Quantitative Finance, 11(7), 991-1012.

Conlon, T., Ruskin, H.J. \& Crane, M. (2009).Cross-correlation dynamics in financial time series. Physica A, 388(5), 705-714.

Coronado, S. \& Gatica, A.L. (2011). Identificación de episodios de dependencia no lineal en el peso mexicano. Cuadernos de Economía, 30(55), 91-104.

Czamanski, D., Dormaar, P., Hinich, M. \& Serletis, A. (2007). Episodic nonlinearity and nonstationarity in Alberta's power and natural gas markets. Energy Economics, 29(1), 94-104.

De Gooijer, J. \& Sivarajasingham, S. (2008). Parametric and Nonparametric Granger Causality Testing: Linkages between International Stock Markets. Physica A: Statistical Mechanics and its Applications, 387(11), 2547-2560.

Diamandis, P. \& Drakos, A. (2011). Financial Liberalization, Exchange Rates and Stock Prices: Exogenous Shocks in Four Latin America Countries. Journal of Policy Modeling, 33, 381-394.

Diks, C. \& Panchenko, V. (2006). New Statistic and Practical Guidelines for Parametric Granger Causality Testing. Journal of Economics Dynamics and Control, 30(9-10), 1647-1669.

Doong, S. C., Yang, S.Y., \& Wang, A. T. (2005). The Emerging Relationship and Pricing of Stocks and Exchange Rates: Empirical evidence from Asian Emerging Markets. Journal of American Academy of Business, 7(1), 118-123.

Gärtner, M. \& Wellershoff, K.W. (1999). Theories of Political Cycles: Lessons from the American Stock Market. Rivista Internazionale di Scienze Economiche e Commerciali: RiSEC, 46, 613-630.

Granger, C., Huang, B., \& Yang, C. (2000). A Bivariate Causality between Stock Prices and Exchange Rates: Evidence from Recent Asian Flu. The Quarterly Review of Economics and Finance, 40, 337-354.

Guzmán, P. M., Leyva, L. S. \& Cárdenas, A. (2007). La relación de causalidad entre el índice bursátil mexicano y el tipo de cambio spot. Análisis Económico, 22(51), 81-105.

Hinich, M. J. (1996). Testing for Dependence in the Input to Linear Time Series Model, Journal of Nonparametric Statistics, 6, 205-221.

Hinich, M.J. (1982). Testing for Gaussianity and Linearity of a Stationary Time Series. Journal of Time Series Analysis, 3, 169-176.

Hinich, M.J. \& Patterson, D.M (1985). Evidence of Nonlinearity in Daily Stock Returns, Journal of Business and Economic Statistics, 3, 69-77.

Hinich, M.J. \& Serletis, A. (2007). Episodic Nonlinear event Eetection in the Canadian Exchange Rate. Journal of the American Statistical Association, 102(477), 68-74.

Hsieh, D.A. (1991). Chaos and Nonlinear Dynamics: Application to Financial Markets. Journal of Finance, 46, 1839-1877.

Huang, R. D. (1985). Common Stock Returns and Presidential Elections. Financial Analyst Journal, 41, 58-61.

Joseph, N.L. (2002). Modelling the Impacts of Interest Rate and Exchange Rate Changes on UK Stock Returns. Derivatives use, Trading and Regulation, 7(4), 306-323.

Kosfeld, R. \& Robé, S. (2001). Testing for Nonlinearities in German Bank Stock Returns. Empirical Economics, 26, 581-597. 
102 Nueva Época REMEF (The Mexican Journal of Economics and Finance)

Laloux, L, Cizeau, P., Bouchaud, J. \& Potters, M. (1999). Noise Dressing of Financial Correlation Matrices. Physical Review Letters, 83(7), 1467-1470.

Lim K. P., 2007, Ranking of Efficiency for Stock Markets: A Nonlinear Perspective. Physica A, 376, 445-454.

Lim, K. P. \& Hinich, M. (2005). Cross-Temporal Universality of Non-Linear Serial Dependencies in Asian Stock Markets. Economics Bulletin, 7(1), 1- 6.

Lim, K.P. \& Brooks, R. (2011). The Evolution of Stock Market Efficiency over Time: A Survey of the Empirical Literature, Journal of Economic Surveys, 25(1), 69-108.

Marinnazo, D., Pellicoro, M. \& Stramaglia, S. (2008). Kernel Method for Nonlinear Granger Causality. Physical Review Letters, 100(14), 1-4.

Mishra, A., Swain, N. \& Malhotra, D. (2007). Volatility Spillover between Stock and Foreing Exchange Markets: Indian Evidence. International Journal of Business, 12(3), 343-359.

Nakayama, Y. \& Iyetomi, H. (2008). Analysis of Dynamical Cross Correlation in Financial Time Series. + Working Paper The 7th International Conference on Computational Intelligence in Economics and Finance, Taoyuan, Taiwan.

Opong, K.K., Mulholland, G., Fox, A.F. \& Farahmand, K. (1999). The Behavior of some UK Equity Indices: An application of Hurst and BDS Tests. Journal of Empirical Finance, 6, 267-282.

Pan, M., Fok, R. \& Liu, Y. (2007). Dynamic linkages between Exchange Rates and Stock Prices: Evidence from East Asian Markets. International Review of Economics and Finance, 16, 503-520.

Panagiotidis, T. (2005), Market Capitalization and Efficiency. Does it matter? evidence from the Athens Stock Exchange. Applied Financial Economics,15(10), 707-713.

Panagiotidis,T. \& Pelloni, G. (2003). Testing for Non Linearity in the Labour Markets: The Case of Germany and the UK. Journal of Policy Modeling, 25(3), 275-286.

Plerou, V., Gopikrishnan, P., Rosenow, B., Amaral, L., Guhr, T. \& Stanley, H. (1999). Universal and Non-Universal Properties and Cross Correlations in Financial Data. Physical Review Letters, 83(7), 1471-1474.

Romero-Meza, R., Bonilla, C.A. \& Hinich, M.J. (2007). Nonlinear Event Detection in the Chilean Stock Market. Applied Economics Letters, 2007. 14, 987 -991.

Santa-Clara, P. \& R. Valkanov.(2003). The Presidential Puzzle: Political Cycles and The Stock Market. Journal of Finance, 58 (5), 1841-1872.

Scheinkman, J. \& LeBaron, B. (1989). Nonlinear Dynamics and Stock Returns, Journal of Business, 62, 311-337.

Serletis, A., Malliaris, A.G., Hinich, M.J. \& Gogas, G. (2012). Episodic Nonlinearity in Leading Global Currencies. Open Economics Review, 23: 337-357.

Sharifi, S., Crane, M., Shamaie, A., \& Ruskin, H. J. (2004). Random Matrix Theory for Portfolio Optimization: A Stability Approach. Physica A, 335 (3-4), 629-643.

Tóth, B. \& Kertész, J. (2005). Increasing Market Efficiency: Evolution Cross-Correlations of Stock Returns. Physica A, 360 (2), 505-515.

Umstead, D. (1977). Forecasting Stock Market Prices. Journal of Finance, 32, 427-448.

Wilcox, D. \& Gebbie, T. (2007). An Analysis of Cross-Correlations in and Emerging Market. Physica A: Statistical Mechanics and its Applications, 375(2), 584-598

Yang, S. \& Doong, S. (2004). Price and Volatility Spillovers between Stock Prices and Exchange Rates: Empirical Evidence from the G-7 Countries. International Journal of Business and Economics, 3(2), 139-153.

Yau, H, Y. \& Nieh, C. (2006). Interrelationships among Stock Prices of Taiwan and Japan and NTD/Yen Exchange Rate. Journal of Asian Economics, 17, 535-552. 